\title{
Criteria and methodology for an indicator of energy applied to motorways
}

\author{
M. J. González Díaz \& J. García-Navarro \\ Departament of Construction and Rural Roads, \\ Universidad Politécnica de Madrid, Spain
}

\begin{abstract}
The environmental impact of roadways is considered really important. Nevertheless, to establish a field of comparison some measures and parameters are needed. Those parameters allow, first, to establish sustainable criteria to develop new civil works, and secondly, they can suggest the best choice and options for any particular case.

Sustainability itself and proper civil works are very complex concepts. The present methodology establishes criteria which allow unifying this complexity from a general point of view. As an example, this methodology will be applied to find out an indicator which measures the embodied energy along all the life cycle in the motorway. This indicator is open to be extended to and joined to other indicators, to reach the whole scope of sustainability.

What is new in this methodology is the consideration of the motorway as a whole dimension and scope, to research its whole life cycle. This means that the aim is to include, in one single index, the embodied energy in the cycle of its whole useful life (project, construction, maintenance and demolition) and in the multiple aspects in which this index, including traffic, is appropriate. This considers the energetic consumption produced directly or indirectly by:

- The act of construction and the materials used in highways, including tunnels and all structures, and extra services and toll facilities.

- The energy utilized through management, periodic maintenance of all the previously mentioned elements and the energetic consumption of all vehicles that use the highway.

- The energetic implication in the deconstruction or demolition of the highway, and the hypothetic recuperation of the natural space affected.
\end{abstract}


The project is established inside the $\mathrm{R}+\mathrm{D}+\mathrm{I}$ (Research and Development and Innovation) named Oasis, (Operation for Safe, Smart and Sustainable Highways), promoted by the Spanish Ministry of Science and Innovation.

Keywords: energy efficiency, methodology, indicator, motorways.

\section{Introduction}

The $\mathrm{R}+\mathrm{D}$ project called Operación de Autopistas Seguras, Inteligentes y Sostenibles (OASIS) [Operation Safe, Intelligent and Sustainable Motorways] aims to define the motorway of the future. This motorway will provide greater safety, user services and sustainability. This programme commenced in the last quarter of 2008 and will conclude in 2011.

Within this comprehensive and global focus, and within the contribution to the motorway's sustainability, the project presented here specifically focuses on the reduction of its energy footprint.

The growing need to improve the efficiency of energy processes has instigated an interest and commitment in all social and administrative fields. This interest, tested in the construction sector, is now starting to come about in public works, specifically in motorways, where previous studies along these lines have yet to be performed [1].

Overall, the aim is to create an index that catalogues motorways relative to their energy balance, taking into consideration its complete lifecycle and all aspects which can calculate energy consumption and insumption. The research for developing this index has given way to a new methodology, whose basic structure is presented here in this study.

\section{Aims}

The general and final aim of the study consists in calculating the energy associated throughout a motorway's complete life cycle, obtaining its "energy footprint."

Calculating this index allows us to also reach other secondary aims, like:

- Obtain a new factor for defining a motorway, offering information to reduce the energy footprint, contributing to the decrease of the consequences of climate change and a lower dependence on foreign energy.

- Pre-evaluate and recognise the expected energy impact of specific stretches in the pre-design and design phase.

- Generate a study on technical-practical alternatives that allow for energy efficiency in the consumption and generation of energy throughout a motorway's complete energy cycle.

- Enter qualitative data relative to sustainability in the selection process of offers for new motorway projects.

For all of this, first a methodology capable of considering all scenarios and fields is proposed, both spatial and temporal, which influence in the transformation of 
the energy generated to create a motorway, and organise them in a single index to approach the previously mentioned aims.

This methodology, created to define an energy index, could then be replicated to provide other indexes. The joint consideration of this energy efficiency index and other indexes would allow for an evaluation of a project's sustainability, seeing it as the one to simultaneously satisfy social, environmental and economic aspects. The greater number of sustainability aspects, the less partial this evaluation will be.

Quantification of the energy footprint will be carried out by implementing a simple software program that evaluates the energy index to then catalogue motorways.

\section{Background}

There are some studies similar to this project's theme, while there are few that hope to come up with an overall approximation of all aspects involved in the project. Some of the existing methodologies applied in the environmental study include the ISO Methodology, along with the list in the Environmental Impact Evaluation.

There are other European environmental impact studies associated to construction processes and the evaluation of the energy incorporated in public works construction materials, like those studies in Switzerland (Oekoinventare, École Polytechnique Fédérale de Zurich), Germany (Universidad de Karlsruhe, Oekoinstitut de Weimar) and France (Cimbeton - Centre d'information sur le ciment et ses applications- y EQUER -Centre Énergétique et Procédés de l'Ecole des Mines de Paris). Applied to Spain, the BEDEC database (Banco Estructurado de Datos de Elementos Constructivos [Structured Construction Elements Database]), from the ITEC (Instituto de Tecnología de la Construcción de Cataluña) has information concerning the energy consumption of the construction elements used in civil engineering during construction.

There are also interesting studies on the energy associated to traffic from an automobile sector's point of view. As an example, the Finnish studies can be cited [2].

Finally, the specific tools for the environmental evaluation of the buildings (VERDE, LEED, BREEAM, HQE, etc), may help as references to similar processes in terms of space and time, but applied differently, since public works and specifically roadways have very different characteristics than that of construction. Either way, these already existing procedure's methodologies have been used as reference.

\section{Methodological bases}

The methodology developed must contemplate a series of basic aspects:

- They must apply a life-cycle analysis (LCA), with a global perspective on time and the fields of action. 
- They must consider a complete panorama that foresees the energy impacts throughout the whole process, providing a complete before and after picture of the motorway in the environment.

- Within this general panorama, the energy index must consider the balance between the energy consumed throughout the process and also the energy produced by the motorway in all its phases. The ultimate aim is a neutral or equilibrated balance of both energies, so that the energy impact is null. This involves considering Ex-energy (consumption, energy expended) and In-energy (insumption, energy produced) must be considered.

- Upon applying the ISO methodology, the alternatives must be understood, to be able to go back in the process and manage the variables to obtain the best results.

\section{Process to develop the energy index (I)}

Since this methodology aims to be applicable on any road, a complex process must be defined and organised so that all possible operations (motorways) may be systemised. For this, the terms "scenario" and "functional unit" are defined to allow us to establish the hypothetical alternatives amongst the solutions. The process is described in four steps.

\subsection{Establishing Scenarios (E)}

A "Scenario" (Escenario, E) is defined by all fixed elements that have no possible alternatives. This is conditioning data on the offer up for bid, which all projects must fulfil. They describe the already fixed situations determined by the intervention.

The scenario is to be defined relative to the climatic and geographic conditions and the type of intervention, etc. via a study prior to developing the road.

One of the characteristics is the area's climate and geomorphology, since:

- Relative to the climate's severity, the zones are distinguished by their viability during winter, pluviometry, etc.

- The orography may be distinguished by terrain slope: Flat, rolling, hilly, very hilly, etc.

- From the geological point of view: the terrain and land type and characteristics.

Within the scenario the road's specific characteristics must also be kept in mind. Along with type of road (motorway, A-road, fast lane); type of intervention (new stretch, duplication, conditioning or local improvements); etc.

And even more influentially, to be determined by previous studies, the expected traffic type and intensity, composition and age of vehicles that use the motorway, etc. 
Once having analysed the scenarios, a homogeneity coefficient (C) applied to each scenario (E) must be determined to establish possible comparisons between different scenarios, if the case arises.

A scenario example could be $E_{1}$ : Motorway stretch between the cities $V_{1}$ and $V_{2}$, on hilly, type $\mathrm{B}_{2}$ land, for $\mathrm{T} 0$ traffic, in climate zone $\mathrm{D} 3$.

\subsection{Defining Functional Units (UF)}

It is important that the scenarios' units to be compared be systemised and simplified. "Functional Units" (Unidad Funcional, UF) are elements within the motorway's design with optional features, and that make up part of the structural repertoire of all stretches.

They are defined and selected by the project leader for the stretch or road. These units allow for the selection, replica, systemisation, serialisation and association in design, making up the list of units that make up the motorway [3].

Each Functional Unit is associated to an energy index (I), as described in the following section. The set of functional units in the stretch are susceptible to comparison with the stretches of different offering parties or of the different possible solutions.

The list of functional units is defined to simplify the routine list of motorway elements in terms of number of accessible units and the commonly used solutions on the motorway: stretches, intersections, tunnels, etc., with unique differences between structure type and morphology, width and number of roadways, hard shoulders, length, light sizes, etc. The functional units characteristics must be distinguished (curve radii, levelling height, side of the road...) and their magnitudes (length of stretch, kilometre points, number of viaducts...).

Functional units will include the necessary accessories and buildings, like tolls, control, service and maintenance buildings, service stations, warehouses, etc.

A motorway could be defined, for example, as follows: Scenario $\mathrm{E}_{1}$, a 10.48 $\mathrm{Km}$ long motorway stretch $\left.\mathrm{UF}_{(\mathrm{t} 01}\right)$, with 2 tunnels $\mathrm{UF}\left(\mathrm{n}_{25}\right), 11$ transversal drainage sites $\mathrm{UF}\left({ }_{\mathrm{d} 22}\right)$ and 20 structures, of which 6 are viaducts $\mathrm{UF}\left({ }_{\mathrm{v} 12}\right), 1$ being an underpass $\mathrm{UF}\left({ }_{\mathrm{s} 02}\right), 3$ being overpasses $\mathrm{UF}\left({ }_{\mathrm{i} 03}\right)$, and 10 being trumpet interchanges $\mathrm{UF}\left({ }_{\mathrm{e} 05}\right)$.

The Functional Unit FU $\left(_{\mathrm{t} 01}\right)$ is defined as: The $1 \mathrm{Km}$ stretch of the motorway, with a $30 \mathrm{~m}$ path, with two roads, two lanes and shoulders, on firm, sloping land and specific compositions.

\subsection{Applying the LCA to the UF}

The aim of this phase is to calculate the energy transformed throughout the lifecycle of each Functional Unit, $\mathrm{UF}(\mathrm{x})$.

Besides the calculation of the energy consumed (ex-energy) it is also necessary to calculate the amount of energy that may be produced (in-energy) in this same functional unit UF. Once calculated the energy consumed EUF (ex) and the energy produced IUF (in) in each of the phases of the functional unit 
(construction, exploitation and demolition), the balance will determine the functional unit index I(UF) $)_{(x)}$ in energy units.

This energy index of the functional unit is calculated in all regular phases in the LCA: Construction project, exploitation and end of life or demolition, considering a period of 30 years. This life period has been defined conventionally, since it is the most often used in the bibliography [4].

\subsubsection{Project construction phase}

For the ex-energy calculation, the energy embedded in the materials is considered, (including the extraction of raw materials, moving land, transport, construction, etc.) [5], and the construction systems and processes both of the roadway and the corresponding surrounding buildings, etc, including all of the management operations typical of the transformation of the original space in a roadway.

In calculating in-energy, the energy produced during the construction process, if any, included are.

\subsubsection{Maintenance phase, exploitation or use of the road}

In the calculation of ex-energy, consumption throughout the exploitation period is considered, from the moment construction has concluded to the start of dismantling.

This includes the maintenance of the public works and buildings, including the surveillance, management, repair and maintenance operations of all of the services of the motorway, including internal maintenance traffic and installation reforms, repavement and asphalting, power generation consumption, lighting, pumping, internal water consumption and annexed building maintenance like control, toll and service buildings.

This chapter on the calculation of energy also includes the energy consumption of transporting passengers and merchandise, in terms of direct consumption (energy consumed for moving vehicles, the use of auxiliary services, lighting, heating system, air-conditioning, any energy lost in the motor and transmission, and indirect consumption (the repercussions of energy embedded in the production of vehicles, etc.) This section discusses the energy consumption of the expected vehicles and relative to the already defined "scenario's" characteristics, along with the motorway's specifics, like the road's surface, slope, occupation, etc. [6-8].

In calculating energy production (In-Energy), it is clear that in this phase of exploitation it may be generated via the systems in this study. Some include the production of photovoltaic generation, anti-noise screens, and solar farms in surrounding areas; the recuperation of energy from the surfaces heat, from the traffic's gas combustion, etc.

\subsubsection{Demolition phase or dismantling}

The ex-energy includes the consumption of demolition or road lifting processes. The generation of heat from waste in recycling plants and the valuation of this waste could be considered in-energy in this phase. 


\subsection{Application of the partial rates in the final calculation}

The motorway would be defined via the list of its functional units (UF). The scenario (E), as previously mentioned, depends on the motorway's initial conditions, and may not be modified by the designer.

Resulting from this previously discussed work, the energy rate for each functional unit I(UF) is determined.

Having defined the scenario, list and combination of functional units that make up the motorway, the balance between the ex-energy and in-energy rates of the total functional units, having applied the $\mathrm{C}$ homogenization coefficient on scenario E, results in the Energy Footprint Index (Índice de Huella Energética, IHE)

$$
\mathrm{IHE}=\mathrm{C}(\mathrm{E}) \Sigma[\mathrm{IUF}(\mathrm{ex})+\operatorname{IUF}(\text { in })]_{(\mathrm{x})}
$$

\section{Results and conclusions}

As previously stated, this study is currently in its second year of progress, hoping to be completed by 2011. Currently the discussed methodology is being applied to evaluate a single functional unit, specifically the Functional Unit FU (t01) defined in chapter 5.2 as: The $1 \mathrm{Km}$ stretch of the motorway, with a $30 \mathrm{~m}$ path, with two roads, two lanes and shoulders, with the aim of validating and verifying its proper performance.

With this first functional unit, the tool's efficacy can be checked in a complete analysis.

With the results obtained in this analysis, the final consumption and energy balance can be valuated, identifying the best techniques from the point of view of energy efficiency in all phases of the infrastructure's life cycle. This tool allows for proposing and promoting initiatives and alternatives that contribute to reducing consumption, and as a result, the road's energy footprint, contributing to the whole process' sustainability.

The final aim is the processes' energy efficiency, both constructive and operational, along with the generation of energy from renewable resources, facilitating a neutral or even positive energy balance in considering the overall life cycle of a road or motorway.

\section{References}

[1] Potential of the Ecological Footprint for monitoring environmental impacts from natural resource use. Analysis of the potential of the Ecological Footprint and related. European commission DG Environment, 2008.

[2] Mroueh U.; Eskola, P. ; et all. Life cycle assessment of road Construction. Finnish National Road Administration. Finnra Reports 17/2000. Helsinki 1999.

[3] Kraemer, C.; Pardillo, J.M.; Rocci, S.; Romana, M.G.; Sánchez Blanco, V.; del Val, M.A. Ingeniería de Carreteras. McGraw-Hill. Madrid, 2003-2004. 
[4] Impacts des Projets de Voirie: L'analyse de Cycle de Vie des Structures Routières. Céntre D'Information sur le ciment et ses applications. Cimbéton Collection technique T89. Paris 2004.

[5] Huang Yue. Development of a life cycle assessment tool for construction and maintenance of asphalt pavements. Journal of Cleaner Production, 1/ 2009.

[6] Spielmann, M.; Scholz, R. Life Cycle Inventories of Transport Services. Background Data for Freight Transport. Swiss Federal Institute of Technology. Zurich, Switzerland 2004. DOI: http://dx.doi.org/10.1065/lca2004.10.181.10

[7] Lenzen, M. Total requirements of energy and greenhouse gases for Australian transport. University of Sydney, 1999.

[8] Van Wee, B et al. Comparing Energy Use and Environmental Performance of Land Transport Modes. Technical University TUDelft, Netherlands 2004. 